\title{
Detection of mycotoxins and toxigenic fungi in cereal grains using vibrational spectroscopic techniques: a review
}

\author{
B. Jia ${ }^{1}$, W. Wang ${ }^{1 *}$, X.Z. $\mathrm{Ni}^{2}$, X. Chu ${ }^{3}$, S.C. Yoon ${ }^{4}$ and K.C. Lawrence ${ }^{4}$ \\ ${ }^{1}$ Beijing Key Laboratory of Optimized Design for modern Agricultural Equipment, College of Engineering, China Agriculture \\ University, No. 17 Tsinghua East Road, Beijing, 100083, China P.R.; ${ }^{2}$ Crop Genetics and Breeding Research Unit, USDA- \\ ARS, 2747 Davis Road, Tifton, GA 31793, USA ${ }^{3}$ College of Mechanical and Electrical Engineering, Zhongkai University of \\ Agriculture and Engineering, Guangzhou 510225, China P.R.; ${ }^{4}$ Quality and Safety Assessment Research Unit, USDA-ARS, \\ Athens, GA 30605, USA; playerwxw@cau.edu.cn
}

Received: 12 August 2019 / Accepted: 17 September 2019

(c) 2020 Wageningen Academic Publishers

OPEN ACCESS @() (1) (1)

REVIEW ARTICLE

\begin{abstract}
Nutrition-rich cereal grains and oil seeds are the major sources of food and feed for human and livestock, respectively. Infected by fungi and contaminated with mycotoxins are serious problems worldwide for cereals and oil seeds before and after harvest. The growth and development activities of fungi consume seed nutrients and destroy seed structures, leading to dramatic declines of crop yield and quality. In addition, the toxic secondary metabolites produced by these fungi pose a well-known threat to both human and animals. The existence of fungi and mycotoxins has been a redoubtable problem worldwide for decades but tends to be a severe food safety issue in developing countries and regions, such as China and Africa. Detection of fungal infection at an early stage and of mycotoxin contaminants, even at a small amount, is of great significance to prevent harmful toxins from entering the food supply chains worldwide. This review focuses on the recent advancements in utilising infrared spectroscopy, Raman spectroscopy, and hyperspectral imaging to detect fungal infections and mycotoxin contaminants in cereals and oil seeds worldwide, with an emphasis on recent progress in China. Brief introduction of principles, and corresponding shortcomings, as well as latest advances of each technique, are also being presented herein.
\end{abstract}

Keywords: vibrational spectroscopy, toxic secondary metabolites, infrared spectroscopy, Raman spectroscopy, hyperspectral imaging

\section{Introduction}

As the most common food staple, cereals and oil seeds collectively provide major sources of dietary calories, including carbohydrates, fatty acids, and proteins, for human and livestock. Cereal grains in form of maize, rice, wheat, and barley constitute a majority of daily sustenance (Orina et al., 2017). Despite many improvements and efforts that have been made in cultivation, harvesting, and storage of cereals and oil crops for a long time, fungal infection remains a serious and challenging problem. The fungi present in grains can cause quality changes, such as dull appearance, musty odour, germ damage, and poor seed germination, leading to reduced edible and huge economic losses (Senthilkumar et al. 2016a,b).
Mycotoxin contamination in cereals and oil crops is caused by secondary metabolites produced by fungi, mainly belonging to species of the genera Aspergillus, Fusarium and Penicillium, and pose serious threats to the health of human and livestock (Wagacha and Muthomi, 2008; Jin et al., 2009). Highly prevalent and critically important mycotoxins include aflatoxins (AFs), ochratoxins (OTs), deoxynivalenol (DON) and fumonisins (FBs), among other toxins described by Pascale (2009) and Selvaraj et al. (2015). The United States Food and Drug Administration (FDA), the European Union, the FAO as well as many other countries, including China (Zhang et al., 2014), have regulated mycotoxin concentration levels both in food and feed. 
AFs are a group of carcinogens associated with liver and lung cancer in humans and mainly produced by Aspergillus flavus and Aspergillus parasiticus (Yao et al., 2010). Among the 18 types of AFs that have been identified, aflatoxin $B_{1}$ $\left(\mathrm{AFB}_{1}\right)$ is considered to be the most toxic, and together with aflatoxin $\mathrm{B}_{2}\left(\mathrm{AFB}_{2}\right), \mathrm{G}_{1}\left(\mathrm{AFG}_{1}\right)$ and $\mathrm{G}_{2}\left(\mathrm{AFG}_{2}\right)$ constitutes the four major AFs that contaminate cereals and oil crops (Gupta et al., 2013; Turner et al., 2009). According to previous aflatoxin outbreaks it is estimated that, when consumed for 1 to 3 weeks, a dose of 20 to $120 \mu \mathrm{g} \mathrm{AFB} / 1 \mathrm{~kg}$ body weight per day is acutely toxic and potentially fatal. OTs are a group of secondary metabolites that are mainly produced by different Aspergillus and Penicillium species. Distinguished by chemical structures, the ochratoxin family contains three members: ochratoxin A (OTA), B, and C (Todscato et al., 2014). OTA is considered to be the most prevalent and harmful, and can cause immunosuppression and immunotoxicity in animals (Lea et al., 1989). DON, also known as vomitoxin, is one the major secondary metabolites produced by Fusarium species. It is predominantly found in cereal grains, such as wheat, barley, and maize (Liu et al., 2009). DON not only decreases grain yield and quality, but also poses a great health risk to human and livestock who have consumed DON-contaminated food or feed products (Leonard and Bushnell, 2004). The most sensitive physiological parameter for animals to low-level DON exposure is the emetic response (Pestka and Smolinski, 2005). FBs, another group of mycotoxins derived from various species of the genus Fusarium, are commonly found on cereals grown in the northern temperate regions of America, Europe, and Asia (Creppy, 2002; Yazar and Omurtag, 2008).

A number of reliable, specific and sensitive analytical methods, such as culture and colony techniques (Gourama and Bullerman, 1995), the PCR-methods (Burlakoti et al., 2007; Ur-Rahman et al., 2020), chromatographic technologies (Martos et al., 2010; Thiex et al., 2009), mass spectrometry (MS) (Sforza et al., 2006), and enzyme-linked immunosorbent assays (ELISA) (Liu et al., 2016), have been developed to detect fungal infection and/or mycotoxin contamination in food and feed. However, these traditional methods tend to be time consuming and labour intensive, and require skilled personnel. These methods also need tedious sample preparation before carrying out, making them unsuitable for large-scale non-destructive detection or rapid online sorting applications. To meet the needs of detecting fungal infection, mycotoxin contamination and/ or mycotoxin concentration in cereals and oil seeds, rapid and non-destructive technologies have received extensive attention.

Vibrational spectra result from the interaction of vibrational motions of a molecule with electromagnetic radiation, including the infrared spectrum and the Raman spectrum (Siesler, 2011). They are fingerprints of adsorbed molecules and can be used for chemical identification. Recently, vibrational spectroscopy and imaging techniques, such as infrared spectroscopy (Gaspardo et al., 2012; HernandezHierro et al., 2008; Kaya-Celiker et al., 2015), Raman spectroscopy (Lee et al., 2014a,b), and hyperspectral imaging (Siripatrawan and Makino, 2015; Teena et al., 2014; Wang et al., 2015a,b) have been investigated for application in detecting of toxigenic fungi and/or mycotoxins in food and feed. A brief introduction of these spectroscopic techniques is given in Table 1. This manuscript provides an overview of working principles, applications, advances, and limitations of the aforementioned non-destructive techniques that have been utilised in rapid detection of mycotoxins and toxigenic fungal contamination in major cereal and oil crop varieties (including maize, wheat, barley, rice and peanut). Most reviewed applications in this paper will focus on recent studies that have been conducted in China, but relevant studies performed in other countries will also be selectively presented.

\section{Principles and application of vibrational spectroscopic techniques}

\section{Near infrared spectroscopy}

NIR spectroscopy is a type of vibrational spectroscopy with spectral range from 780 to $2,500 \mathrm{~nm}\left(12,500-4,000 \mathrm{~cm}^{-1}\right)$. The NIR spectrum is produced by the energy absorption of molecular overtones and combination vibrations of chemical bonds, such as $\mathrm{C}-\mathrm{H}, \mathrm{N}-\mathrm{H}, \mathrm{O}-\mathrm{H}$, and C-O (Cen and $\mathrm{He}, 2007)$. All molecules containing these chemical bonds will have a measurable NIR spectrum, making NIR spectroscopy a suitable technique to provide complex structural and chemical component information of a large range of organic materials (Manley, 2014). NIR spectra can be collected in transmittance and reflectance modes according to the type, property, and component of samples under examination (Porep et al., 2015). In order to obtain a spectrum with high signal to noise ratio (SNR), averaging multiple scan results is a common practice. However, due to the complicated chemical composition of organic samples, obtained spectra in NIR frequencies often consist of many overlapping peaks (also known as multicollinearity) (Cozzolino et al., 2013; Manley, 2014). Furthermore, both chemical composition and physical characteristics of samples under investigation will be reflected on the acquired spectral data (Wu et al., 2018). Preparing samples with proper moisture content, uniform particle size, and surfaces as flat as possible, and so on, are of great importance for reducing spectral noises. Grinding samples into powder before analysis may seem a good solution, however, taking the large amount and complex conditions of samples into account, grinding all samples is obviously unrealistic. To overcome this disadvantage of NIR spectroscopy, in addition to the use of advanced computer hardware and high-precision spectroscopy equipment, 
Table 1. Brief description of near-infrared (NIR), mid-infrared (MIR), and Raman spectroscopic, and hyperspectral imaging techniques (HSI).

\begin{tabular}{|c|c|c|c|c|}
\hline & NIR spectroscopy & MIR spectroscopy & Raman spectroscopy & HSI \\
\hline Spectral range & $\begin{array}{l}780-2,500 \mathrm{~nm} \\
\left(12,500-4,000 \mathrm{~cm}^{-1}\right)\end{array}$ & $4,000-400 \mathrm{~cm}^{-1}$ & $4,000-50 \mathrm{~cm}^{-1}$ & $\begin{array}{l}380-2,500 \mathrm{~nm} \\
\left(26,316-4,000 \mathrm{~cm}^{-1}\right)\end{array}$ \\
\hline $\begin{array}{l}\text { Phenomenon } \\
\text { characteristic }\end{array}$ & Absorption & Absorption & Scattering & Absorption \\
\hline Information & $\begin{array}{l}\text { Overtone and combination } \\
\text { bands }\end{array}$ & Fundamental vibrations & $\begin{array}{l}\text { Fundamental vibrations or } \\
\text { rotations }\end{array}$ & $\begin{array}{l}\text { Overtone and combination } \\
\text { bands }\end{array}$ \\
\hline $\begin{array}{l}\text { Type of sample } \\
\text { analysed }\end{array}$ & Organic and inorganic & Organic and inorganic & Organic & Organic and inorganic \\
\hline Advantages & $\begin{array}{l}\text { Little or no sample preparation } \\
\text { needed } \\
\text { Low cost } \\
\text { Low absorption coefficient: } \\
\text { - high penetration depth } \\
\text { permitted } \\
\text { - strongly absorbing and highly } \\
\text { scattering samples allowed }\end{array}$ & $\begin{array}{l}\text { Little or no sample preparation } \\
\text { needed } \\
\text { Stronger absorption bands than } \\
\text { NIR spectroscopy } \\
\text { High specificity, and few overlaps }\end{array}$ & $\begin{array}{l}\text { Narrow bands, and few } \\
\text { overlaps: } \\
\text { - highly specific like a chemical } \\
\text { fingerprint of a material } \\
\text { - good signal-to-noise ratio } \\
\text { (SNR) } \\
\text { Little or no sample preparation } \\
\text { needed } \\
\text { Basically impervious to water } \\
\text { Fast for complete analysis }\end{array}$ & $\begin{array}{l}\text { Little or no sample } \\
\text { preparation needed } \\
\text { Both spatial and spectral } \\
\text { information available } \\
\text { Suitable for qualitative and } \\
\text { quantitative analyses }\end{array}$ \\
\hline Disadvantages & $\begin{array}{l}\text { Broad and overlapping } \\
\text { absorption bands } \\
10-100 \text { times weaker than the } \\
\text { corresponding fundamental MIR } \\
\text { absorption bands } \\
\text { Influenced by chemical and } \\
\text { physical sample properties }\end{array}$ & $\begin{array}{l}\text { Poor sensitivity and accuracy for } \\
\text { low concentrations } \\
\text { Not comparable to NIR } \\
\text { spectroscopy in quantitative } \\
\text { analysis } \\
\text { Not sensitive to some substances } \\
\text { (e.g. } \mathrm{Ne}, \mathrm{Ca}^{2+}, \mathrm{H}_{2} \text { ) }\end{array}$ & $\begin{array}{l}\text { Weak Raman effect: } \\
\text { - sensitive and highly optimised } \\
\text { instruments needed } \\
\text { - unsuitable for fluorescent } \\
\text { samples } \\
\text { Laser source may destroy } \\
\text { samples } \\
\text { Expensive experiment materials }\end{array}$ & $\begin{array}{l}\text { Huge data cube: } \\
\text { - advanced hardware needed } \\
\text { - data pretreatments needed } \\
\text { - effective chemometric } \\
\text { algorithms needed } \\
\text { Expensive instrumentations }\end{array}$ \\
\hline
\end{tabular}

chemometric algorithms are indispensable (Osborne et al., 2006). Chemometric algorithms aim to remove noisy signals as much as possible without losing critical information, and encompass a broad range of methods, such as spectral preprocessing methods, informative wavelength extraction, pattern recognition, and calibration model development (Cen and He, 2007; Cozzolino, 2009; Roggo et al., 2007). Detailed descriptions on these statistical methods can be found in previous studies, ranging from Guyon and Elisseeff (2003) to Cheng and Sun (2015) and Wang et al. (2017).

Fusarium Head Blight (FHB) infection, a major destructive wheat disease, can damage structure and nutrients of wheat, and produce DON. In order to understand the relationships between Fusarium-damaged kernels (FDKs) and DON concentration, Jin et al. (2014) compared single-kernel nearinfrared (SKNIR) estimated FDKs and DON concentration with visually estimated FDKs and gas chromatographymass spectroscopy (GS-MS)-measured DON, respectively. They found that the correlation coefficient between SKNIR-estimated FDKs and SKNIR-estimated DON was the highest $(\mathrm{r}=0.95 ; P<0.001)$, followed by between
GS-MS-estimated DON and visual-estimated, as well as SKNIR-estimated FDKs, with r-values of $0.74(P<0.001)$ and $0.72(P<0.001)$, respectively. Therefore, both visual and SKNIR-estimated FDKs could be used to predict DON concentration in wheat kernels. In their study on using NIR spectra to detect mouldy rice grains, Jin et al. (2016) investigated two variables: temperature and moisture content. The results showed that either low temperature $\left(5{ }^{\circ} \mathrm{C}\right)$ or moisture content $(<13 \%)$ would inhibit fungal growth. However, when the moisture content exceeded $16 \%$, the total number of fungal colonies still increased rapidly, even in a low temperature environment, suggesting that low moisture content is key to preserve quality during grain storage. The established multiple linear regression (MLR) model could predict the number of fungal colonies with a high coefficient of determination $\left(R^{2}\right)$ value of 0.897 .

Compared to NIR spectroscopy mentioned above, Fourier transformed Near Infrared Spectrum (FT-NIR) spectroscopy provides stable spectra and further improves the spectral resolution (Wu et al., 2018). Previous studies have used FT-NIR spectroscopy to detect mycotoxins in 
cereal grains (De Girolamo et al., 2009, 2019; Gaspardo et al., 2012; Peiris et al., 2017). Zhang et al. (2014) applied FT-NIR spectroscopy ranging from $10,000-4,000 \mathrm{~cm}^{-1}$ $(1000-2,500 \mathrm{~nm})$ for the rapid detection of $\mathrm{AFB}_{1}$ in rice grains. Moisture content influences fungal growth and aflatoxin production, and by using FT-NIR they found that less than $13 \%$ moisture is a critical threshold to prevent fungal growth when rice is kept at room temperature. FTNIR spectroscopy proved to be a suitable technique for the detection of $\mathrm{AFB}_{1}$ with concentrations not lower than $20 \mu \mathrm{g} / \mathrm{kg}$. The partial least squares regression (PLSR) model established by standard normal variate and detrending (SNVD) pretreated spectra showed the best performance with $R^{2}=0.87$, and a standard error of prediction (SEP) of $3.211 \%$.

Huang et al. (2015) chose FT-NIR $\left(10,000-4,000 \mathrm{~cm}^{-1}\right)$ in conjunction with chemometric algorithms to discriminate healthy, mouldy, and budding peanuts. Due to nutrient consumption during fungal growth and peanut germination, contents of lipids, proteins, and other substances in mouldy or budding peanuts often changed. Original spectra of different sample groups clearly showed differences in spectral ranges of 8,321-8,560 $\mathrm{cm}^{-1}, 9,041-9,280 \mathrm{~cm}^{-1}$, and $9,521-9,760 \mathrm{~cm}^{-1}$, which were sensitive to second overtone of $\mathrm{N}-\mathrm{H}$ and $\mathrm{C}-\mathrm{H}$ groups. The best discriminate model established by the $k$-Nearest Neighbour (KNN) pattern recognition method obtained an identification rate of $98.84 \%$ for identifying the different peanut groups.

In the research of Peiris et al. (2009), two NIR systems were used to detect NIR absorption spectra of DON, and of healthy and Fusarium-damaged wheat kernels. The spectra of DON with concentrations ranging between 0.5 to $2,000 \mathrm{mg} / \mathrm{kg}$ in acetonitrile solution showed three peaks at 1,408, 1,904, and 1,919 nm. Single healthy and Fusariumdamaged wheat kernels were scanned and recorded in a spectral range of $950-1,650 \mathrm{~nm}$. Shifts of peak positions between the spectra of these two types of samples were observed, which may be caused by changes in the levels of grain structural compounds and contamination of DON (Peiris et al., 2009). These results show that sound kernels and FDKs with different DON levels have distinguishable characteristics in the NIR spectral ranges. Peiris et al. further analysed single wheat kernels contaminated with FHB and DON (Peiris et al., 2010). A PLSR model was developed to estimate DON levels and to divide FDKs into groups of having low (<60 mg/kg) or high ( $>60 \mathrm{mg} /$ $\mathrm{kg}$ ) DON contamination. DON levels of high DON single kernels could be estimated with an $R^{2}=0.87$ and a SEP of $60.8 \mathrm{mg} / \mathrm{kg}$.

Recently, Sirisomboon et al. (2013) developed calibration models using raw and pretreated NIR spectra in conjunction with a PLSR algorithm, to predict the percentage of fungal infection found in rice. Models developed from original spectra for total fungal infection and from maximum normalisation spectra for yellow-green Aspergillus infection, provided the highest prediction accuracies with an $r$ of 0.668 and 0.437 , and SEP of $28.874 \%$ and $18.723 \%$, respectively. Evidently, these unsatisfactory results showed that moisture and starch content in rice could have influenced overall extent of fungal infection (Sirisomboon et al., 2013).

Lim et al. (2018) used the spectral range between 1,175$1,700 \mathrm{~nm}$ to discriminate between normal and Fusariumcontaminated hulled barley, naked barley, and wheat. The correct classification rate (CCR) of the developed discrimination models using raw spectra was over $98 \%$ for all samples, while second and third-order derivative spectral pretreatments improved the accuracy. Therefore, when designing an experiment, in order to obtain a higher accuracy, different parameters should be considered and controlled within the proper ranges.

\section{Mid-infrared spectroscopy}

MIR spectroscopy, covering the spectral range of $4,000-400 \mathrm{~cm}^{-1}(2,500-25,000 \mathrm{~nm})$, is also sensitive to some groups $(\mathrm{C}-\mathrm{H}, \mathrm{O}-\mathrm{H}, \mathrm{N}-\mathrm{H}, \mathrm{C}-\mathrm{O}$, and $\mathrm{C}=\mathrm{O})$ in molecules and often refers to IR spectroscopy. The MIR spectral region can be divided into four regions: the $\mathrm{X}-\mathrm{H}$ stretching region $\left(4,000-2,500 \mathrm{~cm}^{-1}\right)$, the triple bond region $\left(2,500-2,000 \mathrm{~cm}^{-1}\right)$, the double bond region $\left(2,000-1,500 \mathrm{~cm}^{-1}\right)$, and the fingerprint region (1,500-400 $\left.\mathrm{cm}^{-1}\right)$ (Karoui et al., 2010). The absorption in MIR range relies on the fundamental frequency of molecular vibrations (Shen et al., 2018). Very few compounds have the same MIR spectrum, making MIR spectroscopy suitable for qualitative and quantitative determination of chemical components of samples (Su et $a l ., 2017)$. With the development of modern interference IR spectroscopy techniques, the availability of advanced computer technology, and the emergence of powerful chemometric algorithms, IR spectroscopy reappeared as a means of charactering microbial samples (Amiel et al., 2000; Greene et al., 1992; Kaya-Celiker et al., 2014). FTIR spectroscopy in combination with non-invasive reflectance equipment, such as photoacoustic spectroscopy (PAS), diffuse reflectance spectroscopy (DRS), and attenuated total reflectance (ATR) technique has been developed to identify fungal infections and mycotoxin or other residual contaminations in different types of samples (Kaya-Celiker et al., 2016; Kos et al., 2016; Makio et al., 2007; Mariey et al., 2001; Maquelin et al., 2002).

Shen et al. (2016) applied ATR-FTIR to detect $\mathrm{AFB}_{1}$ in brown rice. Rice samples were divided into four categories, containing $\mathrm{AFB}_{1}$ concentrations of $\leq 5 \mu \mathrm{g} / \mathrm{kg}$, between 5 and $50 \mu \mathrm{g} / \mathrm{kg}$, between 50 and $300 \mu \mathrm{g} / \mathrm{kg}$, and $>300 \mu \mathrm{g} / \mathrm{kg}$, respectively. The mean spectra of these four categories did not show significant differences, but in specific spectral ranges, e.g. 1,760-1,730 $\mathrm{cm}^{-1}$, spectral absorption values 
decreased with an increase in $\mathrm{AFB}_{1}$ content. When predicting $\mathrm{AFB}_{1}$ concentrations, the PLSR model performed the best, with a regression coefficient of validation $\left(r_{v}\right)$ of 0.970 and root mean-square error of prediction (RMSEP) of $70.8 \mu \mathrm{g} / \mathrm{kg}$.

Later, Shen et al. compared the applicability of FT-NIR $\left(12,000-4,000 \mathrm{~cm}^{-1}\right)$ and MIR spectroscopy $\left(4,000-600 \mathrm{~cm}^{-1}\right)$ for classification and quantification of total $\mathrm{AFs}\left(\mathrm{AFB}_{1}, \mathrm{AFB}_{2}\right.$, $\mathrm{AFG}_{1}$, and $\mathrm{AFG}_{2}$ ) in brown rice (Shen et al., 2018). Similar to Shen et al. (2016), rice samples containing different levels of AFs were divided into (five) groups. For the classification of samples with varying $\mathrm{AFB}_{1}$ concentration values, the linear discriminant analysis (LDA) model obtained CCR of 96.9 and $90.6 \%$ for NIR and MIR spectroscopy, respectively. The PLSR model for simultaneous detection of $\mathrm{AFB}_{1}, \mathrm{AFB}_{2}$, $A F G_{1}$, and $A F G_{2}$ in rice also obtained satisfactory results for both NIR $\left(r_{v}=0.936-0.973\right)$ and MIR $\left(r_{v}=0.922-0.970\right)$, showing these two techniques could be used as suitable tools for rapid detection of AFs in rice both qualitatively and quantitatively. Jiang et al. (2017) artificially infected peanut kernels with A. flavus, A. parasiticus, and Aspergillus ochraceus, and counted fungal colonies in mouldy samples using ATR-FTIR technique. During the growth of fungi, fatty acids, proteins, and carbohydrates in peanuts were consumed, and the total number of colonies increased accordingly, causing changes to the spectrum intensity and location. Principle components analysis (PCA) was carried out for further analysis. Several bands (e.g. 1,743, 1,726, $1,695-1,543,1,460,1,378$ and $1,131 \mathrm{~cm}^{-1}$ ) related to nutrient composition in peanuts had large weight coefficient in the first three principle components (PCs). The established PLSR model could predict the total number of colonies of multiple strains with an $R^{2}$ for prediction set of 0.9157 and root mean-square error (RMSE) of cross-validation of $0.2080(\mathrm{lg}(\mathrm{cfu} / \mathrm{g}))$. Shen et al. (2019) applied ATR-FTIR for rapid detection of DON concentration in wheat and wheat products. He showed that samples with different DON content had different absorption values at bands of 1,740 , 1,648 and $1,549 \mathrm{~cm}^{-1}$, making these wavebands suitable for quantitative detection of DON. Both PLSR and stepwise multiple linear regression (SMLR) models could effectively predict DON content in samples with an $R^{2}$ and RMSEP for prediction set of 0.86 and $0.426 \mathrm{mg} / \mathrm{kg}$, and of 0.86 and $0.438 \mathrm{mg} / \mathrm{kg}$, respectively.

Kos et al. (2002) was the first to utilise the ATR-FTIR technique for classification of maize infected by Fusarium graminearum. PCA was applied to separate DONcontaminated and ergosterol-contaminated samples from the blank ones. Investigated concentration ranges for ergosterol and DON were $0.73-4.5 \mathrm{mg} / \mathrm{kg}$ and $0-2.6 \mathrm{mg} / \mathrm{kg}$, respectively. Samples with toxin content above $0.31 \mathrm{mg} / \mathrm{kg}$ could be successfully detected with CCR values between 75$100 \%$. In further research, Kos et al. (2003) used a spectral range from 1,800 to $800 \mathrm{~cm}^{-1}$ for all analyses. The detected concentration ranges were $0.31-2.60 \mathrm{mg} / \mathrm{kg}$ for DON and $0.88-3.60 \mathrm{mg} / \mathrm{kg}$ for ergosterol. The CCR value could be up to $100 \%$ for the classification model built by the KNN algorithm. In order to apply these methods in real-life environments and to reflect the inherent variability of the acquired dataset, Kos et al. (2016) chose a large amount of DON-contaminated maize samples with concentrations at the regulatory limit. The bootstrap-aggregated decision tree classifier was able to classify DON-contaminated maize samples at $1,750 \mu \mathrm{g} / \mathrm{kg}$ (set by EU for unprocessed maize) and $500 \mu \mathrm{g} / \mathrm{kg}$ thresholds with an accuracy of 79 and $85 \%$, respectively. When analysing FTIR-ATR spectral characteristics of healthy and Fusarium-damaged wheat kernels, Peiris et al. (2012) noted considerable variation between their pericarp spectra. Spectra of Fusariumdamaged pericarp exhibited higher peak height at 1,160, $1,203,1,313$, and $1,375 \mathrm{~cm}^{-1}$ bands, which were likely caused by the existence of DON and fungi. When endosperm sections of healthy kernels and moderately infected kernels were compared, the variation in band peak characteristics were very limited. It can be concluded from this research that IR spectroscopy can be used to detect DON in the surface tissues of FDKs.

\section{Raman spectroscopy}

Raman spectroscopy was discovered by the Indian physicist Sir Chandrasekhara Venkata Raman, and ranges from at least $50 \mathrm{~cm}^{-1}$ to $4,000 \mathrm{~cm}^{-1}$. This technique involves hitting samples with a monochromatic light source (i.e. laser) and detecting the scattered light, as shown in Figure 1 (Yang and Ying, 2011). Most of the scattered radiation, which is known as Rayleigh or elastic scattering, has the same frequency as the incident beam (Egerton and Hardin, 1975). When an inelastic collision between incident photons and sample molecules occurs, the vibrational or rotational energy of molecules changes, resulting in Raman scattering.

In this process, if some molecules are in their ground energy state and the incident photons lose energy, then scattered photons will be shifted into longer wavelengths (Stokes scattering with lower frequency) (Scotter, 1997; Smith and Dent, 2019). Otherwise, if some molecules are

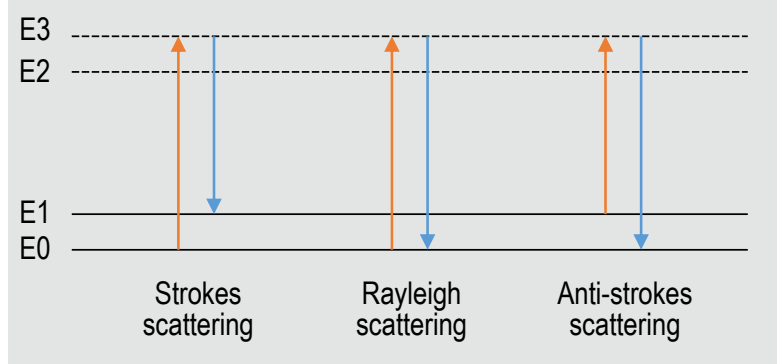

Figure 1. Energy level diagram of Rayleigh and Raman scattering. 
already in vibrationally excited states, then those molecules can contribute energy to the incident beam, resulting scattered photons that contain high energies (shorter wavelengths) than the incident radiation. They contribute to the anti-Stroke bands of the spectrum. Under normal experimental circumstances, the number of molecules in their ground energy state is greater than those in excited states. Therefore, Stokes scattering signals are much more intense than the anti-Stokes scattering signals (Egerton and Hardin, 1975).

Raman scattering relies on changes in the polarisability of chemical bonds, making it sensitive to covalent bonds in non-polar functional groups, such as $\mathrm{C}=\mathrm{C}, \mathrm{C}-\mathrm{C}$ and S-S (Taabu et al., 2015). A typical Raman spectrum is featured by a series of narrow and nonoverlapping peaks. Different compounds have different vibrational spectra, making Raman spectroscopy a powerful tool for qualitative identification through its molecular fingerprint signals (Phillips et al., 1999). Raman spectroscopy can also be used for quantitative determination, because the intensity of Raman bands increases linearly with the analyte concentration (Yang and Ying, 2011). That is, when the molecules to be tested are poor scatterers and/or at low concentration, the intensity of Raman bands will be very weak. To suppress noisy signals (e.g. fluorescence and phosphorescence) and to amplify Raman signals, different Raman spectroscopy systems, such as dispersive Raman spectroscopy, Fourier transform Raman (FT-Raman) spectroscopy, surface-enhanced Raman (SER) spectroscopy, and spatially offset Raman (SOR) spectroscopy are developed and applied for various applications (Kizil et al., 2002; Matousek 2006; Vankeirsbilck et al., 2002; Wu et al., 2012).

Raman spectroscopy has been used as a potential tool to detect fungi or mycotoxins in cereals in recent years. Liu et al. (2009) first explored the feasibility of FT-Raman spectroscopy for rapid screening of DON-contaminated wheat and barley meal. They chose a 1,064 nm NIR excitation laser to reduce interference from fluorescence and photodecomposition of chemical components in wheat and barley. No obviously different peaks could be found between spectra of wheat (or barley) with low DON and high DON, indicating that DON contents at $\mathrm{mg} / \mathrm{kg}$ level did not change the major functional groups and chemical constitutes in wheat and barley. For the purpose of separating samples with low and high DON contents, two Raman bands at 1,560 and $904 \mathrm{~cm}^{-1}$ were selected to develop an intensity-intensity plot. By setting proper threshold intensities for 1,560 and $904 \mathrm{~cm}^{-1}$ bands, 11 of 12 wheat samples with DON $>2 \mathrm{mg} / \mathrm{kg}$ and all wheat samples with DON $<1 \mathrm{mg} / \mathrm{kg}$, and 10 of 11 barley with DON $>6$ $\mathrm{mg} / \mathrm{kg}$ and all barley samples with DON $<1 \mathrm{mg} / \mathrm{kg}$ could be correctly classified separately, which is in agreement with their PCA results. The feasibility of a portable Raman- system based SER scattering for rapid detection DON in cereals was investigated in the study of Yuan et al. (2017). For pure DON solutions, a wide range of detected concentrations between $10^{-7}-10^{-2} \mathrm{M}$ and a limit of detection (LOD) at $100 \mathrm{nM}$ could be reached. When they applied this technique to analyse DON-contaminated maize, the achieved LOD was less than the Chinese standard limits, with a value of $10^{-6} \mathrm{M}$.

Lee et al. (2014a) applied Raman spectroscopy ranging from 200 to $3,500 \mathrm{~cm}^{-1}$ to qualitatively and quantitatively analyse AFs in ground maize samples. Kernels with an aflatoxin concentration range of $0-1,206 \mu \mathrm{g} / \mathrm{kg}$ were divided into five groups. Samples with aflatoxin concentration below $20 \mu \mathrm{g} / \mathrm{kg}$ were treated as the non-contaminated. Just like the Raman spectral characteristics shown in the study of Liu et al. (2009), Raman spectra of maize samples with different AFs concentrations had spectral similarities. Only some bands in several regions showed differences in relative intensity and position. This phenomenon indicates that the effects of physical, chemical, and structural characteristics of grains on the band intensity and sharpness may be more significant than the effects of mycotoxin concentration levels. The best discriminant models developed by LDA did not misclassify any sample with AFs concentration above 20 $\mu \mathrm{g} / \mathrm{kg}$ as aflatoxin negative, and had CCR values in the range of 94-100\%. PLSR models showed the highest $R^{2}(0.941-$ 0.957), but performed poorly when AFs concentration was very low. Later, Lee et al. (2014b) applied SER spectroscopy to detect AFs in maize. The best classification models developed by KNN yielded CCR values in range of 74.3$91.4 \%$ for the validation set, which were not higher - and in fact were even lower - than the classification results in their previous study (Lee et al., 2014a). Lee and Herrman (2016) also analysed the potential and limitation of SER spectroscopy in qualitative and quantitative detection of FB $(0-209 \mathrm{mg} / \mathrm{kg})$ in maize. KNN models yielded a slightly better predictive accuracy than other chemometric classification models with CCR for the validation set in ranges of 70.6-79.4\%. Quantification models established by a MLR algorithm also yielded acceptable predictive ability, with a $R^{2}$ of 0.900-0.940 and RMSEP of 11.162$16.777 \mathrm{mg} / \mathrm{kg}$.

Raman spectroscopy can provide high-sensitive fingerprints for samples, but the high cost of system components, instability of nanostructures, variation in sample batches, and other factors, are still challenges to applying Raman spectroscopy for the detection of mycotoxin-contaminated cereals.

\section{Hyperspectral imaging}

Unlike spectroscopic techniques mentioned in previous sections that can only provide information in spectral domain, hyperspectral imaging (HSI) is able to acquire 
three-dimensional (3-D) datasets that contain two spatial dimensions and one spectral dimension (El Masry et al., 2012b). A 3-D hyperspectral image can be collected in four modes: one pixel at a time, one line at a time, one image of the same wavelength at a time, and the whole data cube at a time. Typically, the line by line collection mode is more often used in the fields of food and agricultural products. The characteristic of being able to provide image information makes hyperspectral imaging a suitable technique for detection of heterogeneous samples. A hyperspectral image may contain hundreds of wavelengths, and each image at the same wavelength usually contains hundreds of pixels. Hardware and software with excellent performance are needed to store and deal with such huge data cubes (El Masry et al., 2012a). More problematic are the irrelevant noises (e.g. background, edge shadows, remained labels, sample holders) and redundant information that are inevitably collected. In order to extract useful information from the acquired hyperspectral images, the following steps of processing (though not covering all aspects and the order is not fixed) are usually needed to go through: (1) calibration with white and black reference images captured from a standard diffuse reflectance surface and a blocked camera lens environment, respectively; (2) cropping out peripherally irrelevant areas and removing low SNR wavebands; (3) image filtering to suppress system and random noises; (4) image segmentation and region of interest (ROI) selection; (5) extraction of spectral and/or spatial features; and (6) further data analysis by applying chemometric algorithms. Those who are interested in detailed descriptions about how to preprocess a hyperspectral image before further analysis can refer to previous studies (e.g. Chen and Qin, 2008; Ravikanth et al., 2017; Vidal and Amigo, 2012). Originating from remote sensing, hyperspectral imaging has enjoyed great growth over the past decades in detection of food safety and quality issues, such as in meat (Barbin et al., 2012; Jia et al., 2017; Zhu et al., 2013), fruit and vegetables (El Masry et al., 2007; Taghizadeh et al., 2011; Yu et al., 2014), cereal grains (Mahesh et al., 2008; Ravikanth et al., 2015), milk (Fu et al., 2014; Munir et al., 2018), and processed foods (Ariana and Lu, 2010; Talens et al., 2013). With regard to detecting fungi and/or mycotoxin contamination in cereal grains, several studies are available (Chu et al., 2017; Wang et al., 2014, 2015b; Williams et al., 2010).

Wang et al. (2014) attempted to detect $\mathrm{AFB}_{1}$ (with concentrations of $10,20,100$ and $500 \mu \mathrm{g} / \mathrm{kg}$ ) on maize surfaces directly using HSI (1000-2,500 nm) accompanied with PCA and stepwise factorial discriminant analysis (FDA). A minimum classification result of $88 \%$ was achieved for the independent validation set, showing that it was possible to discriminate $\mathrm{AFB}_{1}$ at a low concentration of $10 \mu \mathrm{g} / \mathrm{kg}$ on clean maize kernel surfaces. Afterwards, the feasibility of using $\mathrm{HSI}$ to detect $\mathrm{AFB}_{1}$ in a single maize kernel inoculated with conidia in the field, was assessed (Wang et al. (2015b). As shown in Figure 2, interactive analysis based on scatter plot of PC score images was proven to be an effective way to locate and to remove noisy pixels caused by detectors. There are three prominent peaks on the loading line of $\mathrm{PC}_{10-12}$ (Figure 2A), which are located at the same wavelength locations as unusual serrated mutations on the original spectral curves. The 3-D score plots of $\mathrm{PC}_{10-12}$ were rotated and two stray parts of pixels along the axis of $\mathrm{PC}_{10}$ and $\mathrm{PC}_{12}$ were found; these two pixels groups are marked with different colours (Figure $2 \mathrm{~B})$, respectively, and exported as ROIs in the $\mathrm{PC}_{1}$ score image. As shown in Figure $2 \mathrm{C}$, lines with the same colours as ROIs could be found in $\mathrm{PC}_{1}$ score image. By masking these lines, noises in original spectra could be eliminated. Taking into account that information of AFs is trace compared to the information of maize nutrients, researchers reckoned without the first three $\mathrm{PCs}$ and chose $\mathrm{PC}_{4}-\mathrm{PC}_{8}$ to select input data for the spectral angle mapper (SAM) classifier. In the research of Wang et al. (2015b), $\mathrm{PC}_{7}$ tended to be essential in the selection of wavelengths, such as 1,729 and 2,344 nm, which corresponded with $\mathrm{AFB}_{1}$, and the $\mathrm{PC}_{7}$ score image resembled SAM classification result image. Classification accuracies for kernels that contained $\mathrm{AFB}_{1}$ higher than $100 \mu \mathrm{g} / \mathrm{kg}$ or lower than $10 \mu \mathrm{g} / \mathrm{kg}$, all reached values above $80 \%$. However, performance of the classifier for classifying kernels with an $\mathrm{AFB}_{1}$ concentration between 10 and $100 \mu \mathrm{g} / \mathrm{kg}$ was less satisfactory. Therefore, it could be an option to combine multiple techniques for practical detection and/or separation kernels.

In order to identify mouldy peanuts using NIR hyperspectral images (970-2,570 nm), PCA was applied twice in the research of Jiang et al. (2016). Background areas were easily masked due to the great differences between reflectance of background and peanuts. The first PCA was carried out to determine the mouldy-sensitive bands, which had local minimum or maximum values in the eigenvector curves. The first four PCs (denoted by $1 \mathrm{PC}_{1}, 1 \mathrm{PC}_{2}, 1 \mathrm{PC}_{3}$ and $1 \mathrm{PC}_{4}$ in this research) contained most of the information $(99.82 \%)$. However, since $1 \mathrm{PC}_{1}$ mainly reflected information of peanut itself, only eigenvectors of $1 \mathrm{PC}_{2-4}$ were used to select the mouldy-sensitive bands. A second PCA was then carried out on the selected mouldy-sensitive bands. Again, the first four PCs (denoted by $2 \mathrm{PC}_{1}, 2 \mathrm{PC}_{2}, 2 \mathrm{PC}_{3}$ and $2 \mathrm{PC}_{4}$ ) contained the majority of information. $2 \mathrm{PC}_{2}$ and $2 \mathrm{PC}_{4}$ were chosen for further analysis as these two PCs explained the 'mouldy' information of interested. The researchers proposed the following equation to fuse multiple $\mathrm{PC}$ images into one in this study:

Image $=\sum \frac{1}{\mathrm{i} \times \lambda_{\mathrm{i}}} \times 2 \mathrm{PC}_{\mathrm{i}}$

Where $i$ is the order of the chosen PCs, $\lambda_{\mathrm{i}}$ was the $i$-th eigenvalue, and $2 \mathrm{PC}_{\mathrm{i}}$ was the corresponding $\mathrm{PC}$ score image selected from the second PCA. In the resulting image, the 

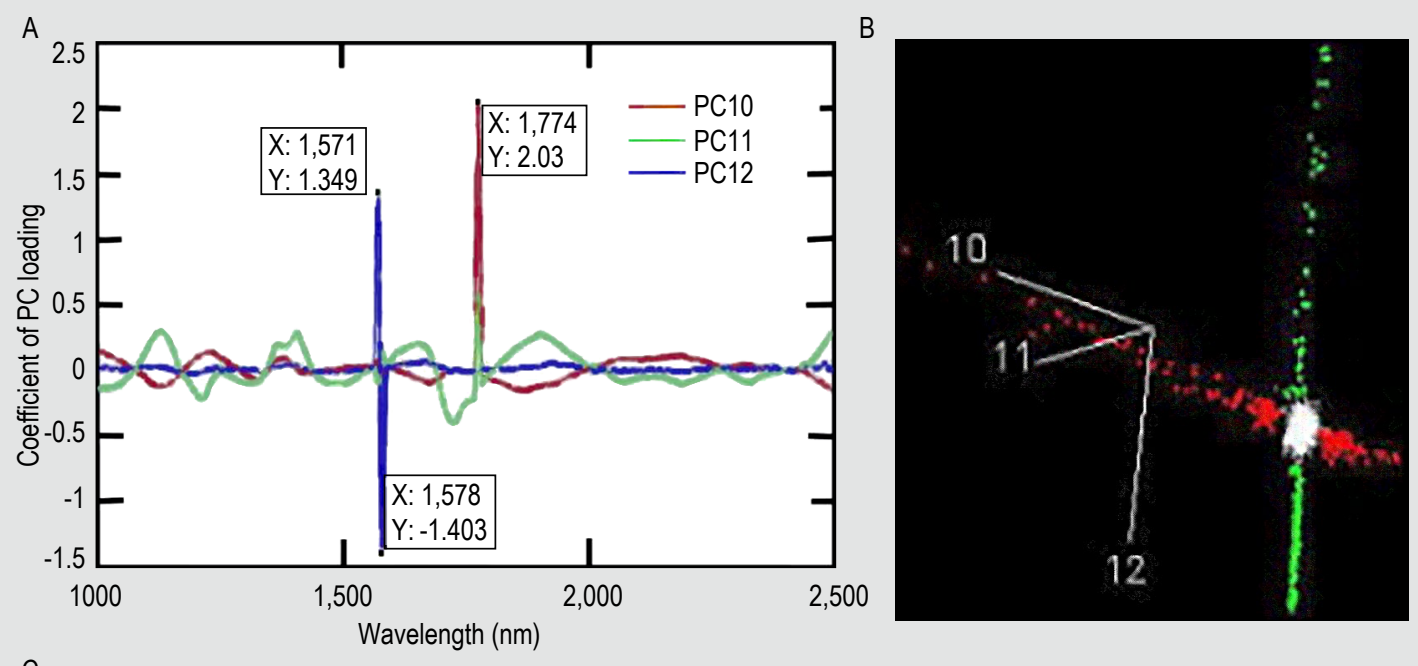

C

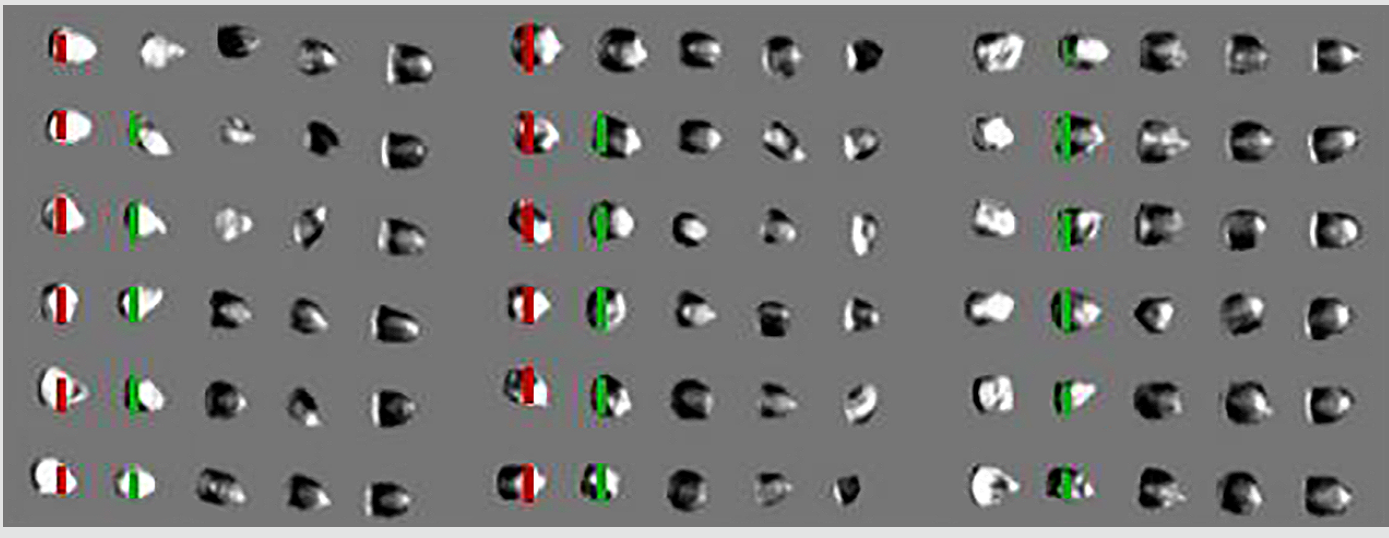

Figure 2. Eliminating noises in hyperspectral imaging using PCA. (A) loading lines of $P_{10-12}$, $(B)$ pixel clusters in the 3-D score image space, $(C)$ corresponding noise lines in the $\mathrm{PC}_{1}$ score image (adapted from Wang et al., 2015b).

pixel value was proportional to the degree of mould. Therefore, mouldy and healthy pixels could be separated by setting a proper threshold $\alpha$ to the image. Taking the fact that healthy pixels may be miscalculated as mouldy ones into account, it is better to set another threshold $\beta$ to assist define a peanut as healthy or mouldy. When ratio of mouldy pixels to total sample pixels exceeds the threshold $\beta$, this peanut could be considered as a mouldy kernel. In the research of Jiang et al. (2016), values for $\alpha$ and $\beta$ were 0.6 and $15 \%$, respectively. Classification accuracy reached $87.14 \%$ in the learning image and $98.73 \%$ in the validation image, showing that the proposed method to merge spectral and spatial information together could be a feasible way to identify healthy and mouldy peanuts. Similarly, Qiao et al. (2017) tried to identify fungus-contaminated peanuts by utilising spectral-spatial features in hyperspectral images. They chose the feature selection method of analysis of variance (ANOVA) and feature extraction method of nonparametric weighted feature extraction (NWFE) to concentrate favourable information together, so that contaminated and healthy peanuts could be separated more easily. In this study, each pixel was classified using a support vector machine (SVM) algorithm. When labelling a sample by calculating the ratio of mouldy pixels to total peanut pixels, the threshold-value $\beta$ was also $15 \%$. The pixel-wise classification accuracies were all above $94 \%$ both in learning and validation images.

The early detection of toxigenic fungi on cereal grains is of great importance to prevent these harmful materials from moving up the food chain. In order to investigate changes caused by fungal contamination on maize kernel surfaces, spectra of different maize hybrids that artificially contaminated with different fungus species were analysed in the research of Del Fiore et al. (2010). Spectra of uncontaminated maize kernels with different moisture values were also obtained and no obvious spectral differences were found, confirming that moisture content did not affect spectral features in the Visible-NIR spectral range. They also noted that kernel colour had a strong impact on spectral signals located in the NIR spectral range. To identify fungal contamination, spectra with 
wavelengths greater than $600 \mathrm{~nm}$ were recommended in order to minimise the influence of pigmentation of kernels. Finally, PCA followed by discriminant analysis allowed discrimination of Aspergillus niger strains on the kernel surface after $2 \mathrm{~d}$ of inoculation. The potential performance of NIR HSI (1000-2,500 nm) for detection of fungal contamination and activity in maize was evaluated in the research of Williams et al. (2012). Eight images $\mathrm{T}_{0}-\mathrm{T}_{8}$ (with $\mathrm{T}_{5}$ absence due to technical issues) were successfully collected at eight specified time intervals $(0,17,20,23$, 26, 43, 69, and $90 \mathrm{~h}$ ) after Fusarium verticillioides spore inoculation. These images together with an image of the control group were merged into a mosaic data cube and PCA was applied to the noise removed image. In the score image of $\mathrm{PC}_{4}$, there were three distinct clusters from left to right which corresponded to pixels from control kernels to inoculated kernels for $90 \mathrm{~h}$, respectively. When these clusters were divided into green, black, and red categories, their corresponding pixels in score image would be control, $\mathrm{T}_{0}-\mathrm{T}_{1}$, and $\mathrm{T}_{2}-\mathrm{T}_{8}$, respectively. PLSR models for the prediction of the degree of infection obtained $R^{2}$ values in the range of 0.8-0.98 for all treatments, indicating that it was possible to monitor changes in fungal infected maize over time.

For the early detection of Fusarium infection in wheat using visible-NIR HSI (400-1000 nm), it was found that spectra over $750 \mathrm{~nm}$ were not relevant to disease detection (Bauriegel et al., 2011). During the whole wheat head development period before harvest, the start of the mid-milk stage was recommended as the best disease determination time. In order to classify healthy and diseased tissues, Bauriegel et al. (2011) proposed a new head blight index (HBI), which indicated the relevant spectral differences in spectral ranges of 550-560 and 665-675 $\mathrm{nm}$. Classification of diseased ears can be performed in a very short time using HBI, making HBI a suitable outdoor classification method. Shahin and Symons (2012) also applied visibleNIR HSI to detect FDKs in Canadian wheat samples. Partial least squares discriminant analysis (PLSDA) was used to separate all samples with varying degrees of infection ranging from sound through mild to severe, into sound and damaged categories. The best PLSDA model could reach high classification results with an overall FDKs detection rate of $90 \%$ and false positive (misclassified sound kernels into damaged group) of $9 \%$. In their research on automatic detection of FHB in wheat kernels, Barbedo et al. (2015) proposed an algorithm to segment single kernels from each other and to calculate a Fusarium index (FI). Mean pixel values of sound and damaged kernels were calculated and a proper threshold was given to separate these two groups. The value of this threshold needs to be adjusted according to the different research environments. FI, which calculates the proportion of pixels in a kernel with values larger than the given threshold, was defined as an indicator of the likelihood of kernels being infected by the FHB.
Combined with PCA, this algorithm overcame factors, such as position, direction, shadow, and cluster of kernels, and finally reached a classification accuracy above $91 \%$.

Before fungi form large colonies, they are invisible to the naked eye. Therefore, scanning electron microscopy (SEM) was used to observe symptoms of Aspergillus oryzae infection on rice in the study by Siripatrawan and Makino (2015). They found that mycelia first appeared on the embryo side and then the endosperm part, which may be due to the higher level of nutrients (e.g. protein, vitamins, and minerals) contained in the embryo. Combined with a self-organising map (SOM), HSI was able to monitor the degree of $A$. oryzae development even when samples were mould-free to the naked eye. PLSR also obtained a good result when predicting fungal development, with a $R^{2}$ value equal to 0.97 .

Kandpal et al. (2015) applied PLSDA models to detect $\mathrm{AFB}_{1}$ concentration in maize with different surface colours. Savitzkye-Golay first derivative preprocessed spectra obtained acceptable accuracy for all three varieties and the highest overall CCR value was $96.9 \%$ for the purple variety. Though a slight misclassification may occur when the $\mathrm{AFB}_{1}$ concentration is lower than $10 \mu \mathrm{g} / \mathrm{kg}$, aflatoxinfree samples could readily be separated from contaminated ones. Senthilkumar et al. (2016a) was the first to apply HSI to the detection of OTA in stored wheat. After carrying out PCA, based on the highest factor loadings of $\mathrm{PC}_{1}$, $1,280,1,300$, and $1,350 \mathrm{~nm}$ were identified as the three significant wavelengths that corresponded to fungal (Aspergilus glaucus and Penicillium spp.) contamination. Again, in another report by Senthilkumar et al. (2016b) to detect fungal infection (A. glaucus and Penicillium spp.) and OTA contamination in stored barley, 1,260, 1,310, and $1,360 \mathrm{~nm}$ were identified to be the wavelengths to detect fungal infection damage in kernels from factor loadings of $\mathrm{PC}_{1}$. These two reports confirmed that $1,480 \mathrm{~nm}$ was only related to OTA in contaminated samples. Statistical and histogram features calculated from significant wavelengths were subjected to classifiers, and the quadratic classifier achieved a higher CCR than linear and Mahalanobis statistical classifiers. OTA-contained wheat and barley samples could all be completely distinguished from OTAfree samples. Satisfied classification accuracies showed that HSI could be a feasibility tool for the detection of different stages of the fungal infection process, as well as different levels of OTA accumulation.

\section{Other techniques}

Due to nutrient consumption, especially protein hydrolysis which often happens in mouldy cereals and oilseed crops, a dull appearance and unsatisfactory odour produced by the infected samples are unavoidable in most cases. Also, AFs will exhibit fluorescence when excited with ultraviolet (UV) 
light sources or NIR laser excitation. Therefore, many other non-destructive detection techniques, e.g. an electronic nose based on electronic sensors to identify specific odour components (Paolesse et al., 2006), fluorescence spectroscopy which analyses the fluorescence properties of certain samples (Hruska et al., 2013; Yao et al., 2013), and image-processing based machine vision (Ataş et al., 2012) could also be used to identify and evaluate fungal growth and mycotoxin contamination. Except for these aforementioned techniques applied in a laboratory environment, researchers have devoted a lot of efforts to the development of non-destructive sorting equipment that can be well adapted to factory scale or online testing environment. In the high-volume grain sorting market, there are different kinds of sorting machines based on colour discrimination, spectral analysis, image processing, and so on. Among this kind of grain sorting equipment, the majority is the colour-based. According to the mode of material transmission, colour sorter machines can be divided into two categories: vertical type and crawler type. Both kinds of equipment can detect the colour changes caused by fungal development and remove them effectively. A colour sorter machine usually consists the following parts: feeding devices, transmission devices, light source, detecting system, controller, and sorting devices.

At the start of the $21^{\text {st }}$ century, colour sorters dominating the Chinese market were imported from Japan (e.g. Satake and Anzai), Switzerland (e.g. Bühler), South Korea and other countries. In recent years, many Chinese brands (e.g. Meyer and Wesort Optoelectronic) that are mainly produced in the cities of Hefei and Shenzhen, begin to meet the Chinese market needs of rapid and non-destructive grain-sorting technology. After decades of development, the techniques for traditional photoelectric colour sorters and charge-coupled device (CCD)-based colour sorters have been relatively mature. However, a critical fact that cannot be ignored is that mycotoxins may be present in some seeds, even if there is no obvious appearance of fungal damage. As in actual storage, it would be a difficult task to prevent cross-infection. Colour sorters will be incompetent to recognise these mycotoxin contaminated seeds.

Therefore, new infrared- and ultraviolet fluorescence-based sorting machines, which can detect both the appearance outside and the chemical composition information inside a seed (or a kernel), are being developed at a fast pace to meet the market demand for improved technologies. In addition to the mainstream structural designs in the market, some research teams are also experimenting with new designs aiming at detecting different samples. For instance, the crawler-type fungal-damaged and toxincontaminated grain sorting machine shown in Figure 3 (Jiang et al., 2018). This machine takes the flat shape of maize into account, as fungi will only grow on one side of a kernel. An arc-shaped turnover device in conjunction with two belts layers was designed to turn maize kernels over, so both kernel sides can be examined. The core component of this sorting equipment is the photodiode-based data acquisition card installed in the detection system. LED lights with different wavelengths are arranged in circle to give uniform illumination. Thus, the photodiode arranged in centre of the lights is able to collect data on the samples. According to previous studies (e.g. Pearson et al. 2004), light sources with different wavelengths can be used in high speed sorting machines to help identify mycotoxincontaminated grains. Thus, by changing the wavelengths of the LED lights, this sorting machine could be used to detect and remove different kinds of mycotoxins contaminating grain.

\section{Conclusions and future trends}

Benefitting from the exciting recent advances in hard-and software technology, vibrational spectroscopic techniques, including infrared spectroscopic and Raman spectroscopic technique have greatly evolved in the past decades. It is apparent that research on rapid detection of fungi and mycotoxins by vibrational spectroscopic techniques started later in China compared to the western countries. However, this special and fast-growing research field still offers many opportunities for contributions by Chinese scientists.

All the spectroscopic techniques have shown satisfactory performances in the laboratory environment, but for largescale applications of these technologies or online automatic applications, there is still a long way to go. The major obstacles that need to overcome are the high cost of the equipment, huge datasets, lengthy processing procedures, and the demand of high detection limits. To fully utilise these spectroscopic techniques further in a commercial market, developing high-speed and low-cost equipment, improving the appropriate modelling robustness in data processing, and increasing the detection sensitivity to meet the demands of detection limits are necessary. In addition, combining multiple techniques in designing new instrument, e.g. X-ray, fluorescence spectroscopy, nuclear magnetic resonance, electronic nose, could be a prudent approach to overcome the shortcomings of an individual technique.

\section{Supplementary material}

Supplementary material can be found online at https://doi. org/10.3920/WMJ2019.2510.

Table S1. Summary description of studies using nearinfrared, mid-infrared, Raman spectroscopic, and hyperspectral imaging techniques. 
A
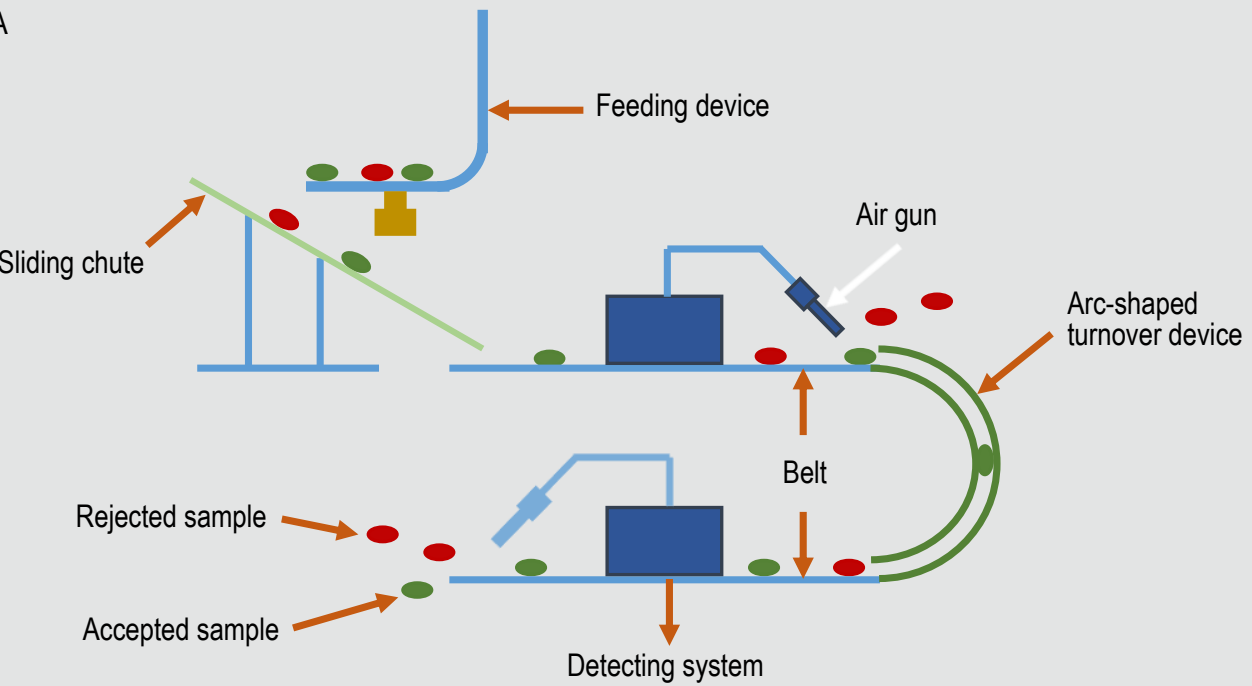

Detecting system

\section{Feeding device}

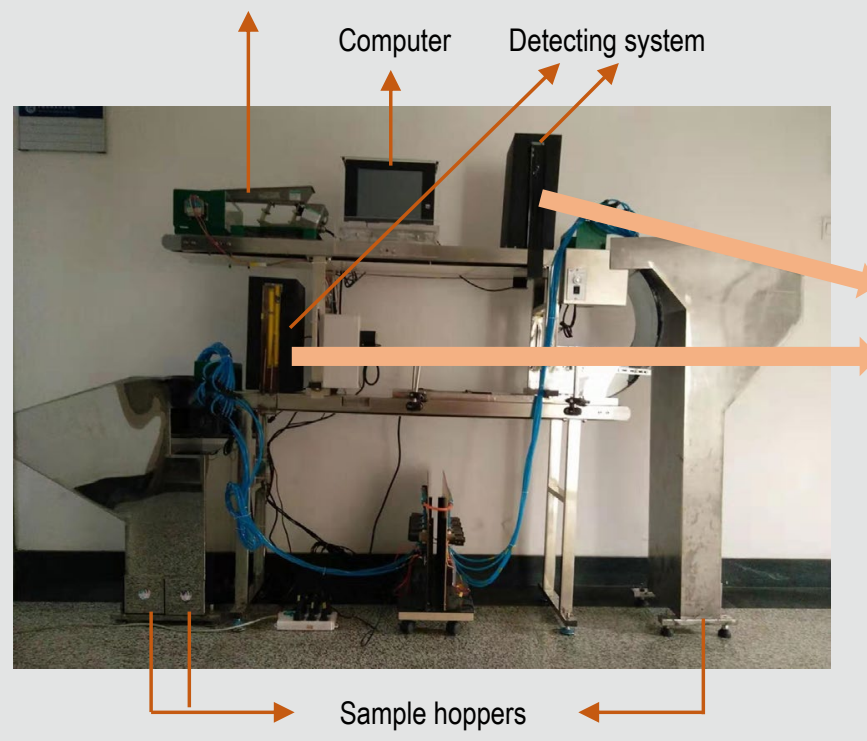

Photodiode-based data acquisition card

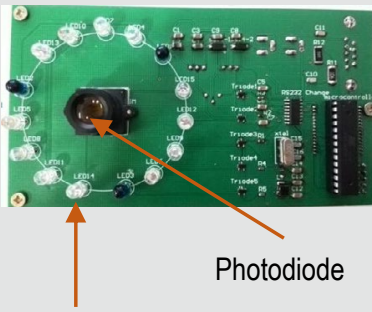

LED light source

Figure 3. The schematic diagram $(A)$ and photo $(B)$ of a belt-based double-side sorting machine for detecting mouldy and toxincontaminated maize kernels, developed by the Non-destructive Detecting Laboratory for Agricultural and Food Products in the College of Engineering at the China Agricultural University.

\section{Acknowledgements}

This work was financially supported by the National Key Research and Development Program of China (2018YFC1603506).

\section{Conflict of interest}

The authors declare no conflict of interest.

\section{References}

Amiel, C., Mariey, L., Curk-Daubié, M.C., Pichon, P. and Travert, J., 2000. Potentiality of Fourier transform infrared spectroscopy (FTIR) for discrimination and identification of dairy lactic acid bacteria. Le Lait 80: 445-459.

Ariana, D.P. and Lu, R., 2010. Evaluation of internal defect and surface color of whole pickles using hyperspectral imaging. Journal of Food Engineering 96: 583-590.

Ataş, M., Yardimci, Y. and Temizel, A., 2012. A new approach to aflatoxin detection in chili pepper by machine vision. Computers and Electronics in Agriculture 87: 129-141. 
Barbedo, J.G., Tibola, C.S. and Fernandes, J.M., 2015. Detecting Fusarium head blight in wheat kernels using hyperspectral imaging. Biosystems Engineering, 131: 65-76.

Barbin, D., Elmasry, G., Sun, D. W. and Allen, P., 2012. Near-infrared hyperspectral imaging for grading and classification of pork. Meat Science 90: 259-268.

Bauriegel, E., Giebel, A., Geyer, M., Schmidt, U. and Herppich, W.B., 2011. Early detection of Fusarium infection in wheat using hyper-spectral imaging. Computers and Electronics in Agriculture 75: 304-312.

Burlakoti, R.R., Rolando Estrada, J., Rivera, V.V., Boddeda, A., Secor, G.A. and Adhikari, T.B., 2007. Real-time pcr quantification and mycotoxin production of Fusarium graminearum in wheat inoculated with isolates collected from potato, sugar beet, and wheat. Phytopathology 97: 835.

Cen, H. and He, Y., 2007. Theory and application of near infrared reflectance spectroscopy in determination of food quality. Trends in Food Science and Technology 18: 72-83.

Chen, K. and Qin, C., 2008. Segmentation of beef marbling based on vision threshold. Computers and Electronics in Agriculture 62: 223-230.

Cheng, J.H. and Sun, D.W., 2015. Recent applications of spectroscopic and hyperspectral imaging techniques with chemometric analysis for rapid inspection of microbial spoilage in muscle foods. Comprehensive Reviews in Food Science and Food Safety 14: 478-490.

Chu, X., Wang, W., Yoon, S.C., Ni, X. and Heitschmidt, G.W., 2017. Detection of aflatoxin $\mathrm{B}_{1}\left(\mathrm{AFB}_{1}\right)$ in individual maize kernels using short wave infrared (SWIR) hyperspectral imaging. Biosystems Engineering 157: 13-23.

Cozzolino, D., 2009. Near infrared spectroscopy in natural products analysis. Planta Medica 75: 746-756.

Cozzolino, D., Roumeliotis, S., and Eglinton, J., 2013. Exploring the use of near infrared (NIR) reflectance spectroscopy to predict starch pasting properties in whole grain barley. Food Biophysics 8: 256-261.

Creppy, E.E., 2002. Update of survey, regulation and toxic effects of mycotoxins in Europe. Toxicology Letters 127: 19-28.

De Girolamo, A., Cervellieri, S., Cortese, M., Porricelli, A.C.R., Pascale, M., Longobardi, F., Holst, C.V., Ciaccheri, L. and Lippolis, V., 2019. Fourier transform near-infrared and mid-infrared spectroscopy as efficient tools for rapid screening of deoxynivalenol contamination in wheat bran. Journal of the Science of Food and Agriculture 99: 1946-1953.

De Girolamo, A., Lippolis, V., Nordkvist, E. and Visconti, A., 2009. Rapid and non-invasive analysis of deoxynivalenol in durum and common wheat by Fourier-Transform Near Infrared (FT-NIR) spectroscopy. Food Additives and Contaminants Part A 26: 907-917.

Del Fiore, A., Reverberi, M., Ricelli, A., Pinzari, F., Serranti, S., Fabbri, A.A., Bonifazi, C. and Fanelli, C., 2010. Early detection of toxigenic fungi on maize by hyperspectral imaging analysis. International Journal of Food Microbiology 144: 64-71. https://doi.org/10.1016/j. ijfoodmicro.2010.08.001

Egerton, T.A. and Hardin, A.H., 1975. The application of Raman spectroscopy to surface chemical studies. Catalysis Reviews Science and Engineering 11: 71-116.
El Masry, G., Barbin, D.F., Sun, D.W. and Allen, P., 2012a. Meat quality evaluation by hyperspectral imaging technique: an overview. Critical Reviews in Food Science and Nutrition 52: 689-711.

El Masry, G., Kamruzzaman, M., Sun, D.W. and Allen, P., 2012b. Principles and applications of hyperspectral imaging in quality evaluation of agro-food products: a review. Critical Reviews in Food Science and Nutrition 52: 999-1023.

El Masry, G., Wang, N., El Sayed, A. and Ngadi, M., 2007. Hyperspectral imaging for nondestructive determination of some quality attributes for strawberry. Journal of Food Engineering 81: 98-107.

Fu, X., Kim, M.S., Chao, K., Qin, J., Lim, J., Lee, H., Garrido-Varod, A., Pérez-Marín, D. and Ying, Y., 2014. Detection of melamine in milk powders based on NIR hyperspectral imaging and spectral similarity analyses. Journal of Food Engineering 124: 97-104.

Gaspardo, B., Del Zotto, S., Torelli, E., Cividino, S.R., Firrao, G., Della Riccia, G., and Stefanon, B., 2012. A rapid method for detection of fumonisins $B_{1}$ and $B_{2}$ in corn meal using Fourier transform near infrared (FT-NIR) spectroscopy implemented with integrating sphere. Food Chemistry 135: 1608-1612.

Gourama, H. and Bullerman, L.B., 1995. Detection of molds in foods and feeds: potential rapid and selective methods. Journal of Food Protection 58: 1389-1394.

Greene, R.V., Gordon, S.H., Jackson, M.A., Bennett, G.A., McClelland, J.F. and Jones, R.W., 1992. Detection of fungal contamination in corn: potential of FTIR-PAS and-DRS. Journal of Agricultural and Food Chemistry 40: 1144-1149.

Gupta, V.K., Tuohy, M.G., Ayyachamy, M., O’Donovan, A. and Turner, K.M., 2013. Laboratory protocols in fungal biology. Laboratory Protocols in Fungal Biology. Springer, New York, NY, USA.

Guyon, I. and Elisseeff, A., 2003. An introduction to variable and feature selection. Journal of Machine Learning Research 3: 11571182.

Hernandez-Hierro, J.M., Garcia-Villanova, R.J. and Gonzalez-Martin, I., 2008. Potential of near infrared spectroscopy for the analysis of mycotoxins applied to naturally contaminated red paprika found in the Spanish market. Analytica Chimica Acta 622: 189-194.

Hruska, Z., Yao, H., Kincaid, R., Darlington, D. and Cleveland, T.E., 2013. Fluorescence imaging spectroscopy (FIS) for comparing spectra from corn ears naturally and artificially infected with aflatoxin producing fungus. Journal of Food Science 78: 1313-1320.

Huang, X., Ding, R. and Shi, J., 2015. Studies on non-destructive testing method of moldy and budding peanuts by near infrared spectroscopy. Journal of Agricultural Science and Technology 17: 27-32.

Jia, B., Yoon, S. C., Zhuang, H., Wang, W. and Li, C., 2017. Prediction of $\mathrm{pH}$ of fresh chicken breast fillets by VNIR hyperspectral imaging. Journal of Food Engineering 208: 57-65.

Jiang, H., Wang, W., Ni, X.Z., Zhuang, H., Yoon, S.C. and Lawrence, K.C., 2018. Recent advancement in near infrared spectroscopy and hyperspectral imaging techniques for quality and safety assessment of agricultural and food products in the China Agricultural University. NIR News 29: 19-23.

Jiang, J., Qiao, X. and He, R., 2016. Use of near-infrared hyperspectral images to identify moldy peanuts. Journal of Food Engineering 169: 284-290. 
Jiang, X.S., Liu, P., Shen, F., Zhou, H. and Chen, Q., 2017. Analysis of moldy peanut kernel by attenuated total reflectance-Fourier transform infrared spectroscopy. Food Science 38: 315-320.

Jin, C., Zhang, Q. and Zheng, X., 2016. Near infrared spectroscopy forecasting model of the total number storage rice mould. Journal of Agricultural Mechanization Research 10: 160-164.

Jin, F., Bai, G., Zhang, D., Dong, Y., Ma, L., Bockus, W. and Dowell, F., 2014. Fusarium-damaged kernels and deoxynivalenol in Fusariuminfected U.S. winter wheat. Phytopathology 104: 472-478.

Jin, J., Tang, L., Hruska, Z. and Yao, H., 2009. Classification of toxigenic and atoxigenic strains of Aspergillus flavus with hyperspectral imaging. Computers and Electronics in Agriculture 69: 158-164.

Kandpal, L.M., Lee, S., Kim, M.S., Bae, H. and Cho, B.K., 2015. Short wave infrared (SWIR) hyperspectral imaging technique for examination of aflatoxin $\mathrm{B}_{1}\left(\mathrm{AFB}_{1}\right)$ on corn kernels. Food Control 51: 171-176.

Karoui, R., Downey, G. and Blecker, C., 2010. Mid-infrared spectroscopy coupled with chemometrics: a tool for the analysis of intact food systems and the exploration of their molecular structure-quality relationships - a review. Chemical Reviews 110: 6144-6168.

Kaya-Celiker, H., Mallikarjunan, P.K. and Kaaya, A., 2015. Mid-infrared spectroscopy for discrimination and classification of aspergillus spp. contamination in peanuts. Food Control 52: 103-111.

Kaya-Celiker, H., Mallikarjunan, P.K. and Kaaya, A., 2016. Characterization of invasion of genus Aspergillus on peanut seeds using ftir-pas. Food Analytical Methods 9: 105-113.

Kaya-Celiker, H., Mallikarjunan, P.K., Schmale III, D. and Christie, M.E., 2014. Discrimination of moldy peanuts with reference to aflatoxin using FTIR-ATR system. Food Control 44: 64-71.

Kizil, R., Irudayaraj, J. and Seetharaman, K., 2002. Characterization of irradiated starches by using FT-Raman and FTIR spectroscopy. Journal of Agricultural and Food Chemistry 50: 3912-3918.

Kos, G., Lohninger, H. and Krska, R., 2002. Classification of maize contaminated with Fusarium graminearum using mid-infrared spectroscopy and chemometrics. Mycotoxin Research 18: 104-108.

Kos, G., Lohninger, H. and Krska, R., 2003. Development of a method for the determination of Fusarium fungi on corn using mid-infrared spectroscopy with attenuated total reflection and chemometrics. Analytical Chemistry 75: 1211-1217. https://doi.org/10.1021/ ac0260903

Kos, G., Sieger, M., McMullin, D., Zahradnik, C., Sulyok, M., Öner, T., Mizaikoff, B. and Krska, R., 2016. A novel chemometric classification for FTIR spectra of mycotoxin-contaminated maize and peanuts at regulatory limits. Food Additives and Contaminants Part A 33: 1596-1607.

Lea, T., Steien, K. and Størmer, F.C., 1989. Mechanism of ochratoxin A-induced immunosuppresion. Mycopathologia 107: 153-159.

Lee, K.M. and Herrman, T.J., 2016. Determination and prediction of fumonisin contamination in maize by surface-enhanced Raman spectroscopy (SERS). Food and Bioprocess Technology, 9: 588-603.

Lee, K.M., Herrman, T.J., Bisrat, Y. and Murray, S.C., 2014b. Feasibility of surface-enhanced Raman spectroscopy for rapid detection of aflatoxins in maize. Journal of Agricultural and Food Chemistry 62: 4466-4474.
Lee, K.M., Herrman, T.J. and Yun, U., 2014a. Application of Raman spectroscopy for qualitative and quantitative analysis of aflatoxins in ground maize samples. Journal of Cereal Science 59: 70-78.

Leonard, K.J. and Bushnell, W.R., 2004. Fusarium head blight of wheat and barley. APS Press, St. Paul, MN, USA.

Lim, J., Kim, G., Mo, C., Oh, K., Kim, G., Ham, H., Kim, S. and Kim, M.S., 2018. Application of near infrared reflectance spectroscopy for rapid and non-destructive discrimination of hulled barley, naked barley, and wheat contaminated with Fusarium. Sensors 18: 113.

Liu, X., Tang, Z., Duan, Z., He, Z. and Xu, Y., 2016. Nanobody-based enzyme immunoassay for ochratoxin a in cereal with high resistance to matrix interference. Talanta 164: 154-158.

Liu, Y., Delwiche, S.R. and Dong, Y., 2009. Feasibility of FT-Raman spectroscopy for rapid screening for DON toxin in ground wheat and barley. Food Additives and Contaminants Part A 26: 1396-1401.

Mahesh, S., Manickavasagan, A., Jayas, D.S., Paliwal, J. and White, N.D.G., 2008. Feasibility of near-infrared hyperspectral imaging to differentiate Canadian wheat classes. Biosystems Engineering 101: 50-57.

Makio, T., Hiroaki, I., Tomohiro, T., Hisaya, Y., Kumiko, N. and Nobuaki, T., 2007. Classification of pesticide residues in the agricultural products based on diffuse reflectance IR spectroscopy. In: SICE Annual Conference 2007. Institute of Electrics and Electronic Engineers, New York, NY, USA. https://doi.org/10.1109/ SICE.2007.4420979

Manley, M., 2014. Near-infrared spectroscopy and hyperspectral imaging: non-destructive analysis of biological materials. Chemical Society Reviews 43: 8200-8214.

Maquelin, K., Kirschner, C., Choo-Smith, L.P., Van den Braak, N., Endtz, H.P., Naumann, D. and Puppels, G.J., 2002. Identification of medically relevant microorganisms by vibrational spectroscopy. Journal of Microbiological Methods 51: 255-271.

Mariey, L., Signolle, J.P., Amiel, C. and Travert, J., 2001. Discrimination, classification, identification of microorganisms using FTIR spectroscopy and chemometrics. Vibrational Spectroscopy 26: $151-159$.

Martos, P., Thompson, W. and Diaz, G., 2010. Multiresidue mycotoxin analysis in wheat, barley, oats, rye and maize grain by highperformance liquid chromatography-tandem mass spectrometry. World Mycotoxin Journal 3: 205-223.

Matousek, P., 2006. Inverse spatially offset Raman spectroscopy for deep non-invasive probing of turbid media. Applied Spectroscopy 60: 1341-1347.

Munir, M.T., Wilson, D.I., Yu, W. and Young, B.R., 2018. An evaluation of hyperspectral imaging for characterising milk powders. Journal of Food Engineering 221: 1-10.

Orina, I., Manley, M. and Williams, P.J., 2017. Non-destructive techniques for the detection of fungal infection in cereal grains. Food Research International 100: 74-86.

Osborne, B.G., 2006. Near-infrared spectroscopy in food analysis. In: Meyers, R.A. and McGorrin, R.J. (eds.) Encyclopedia of analytical chemistry: applications, theory and instrumentation. https://doi. org10.1002/9780470027318.a1018 
Paolesse, R., Alimelli, A., Martinelli, E., Natale, C.D., D'Amico, A., D’Egidio, M.G., Aureli, G., Ricelli, A. and Fanelli, C., 2006. Detection of fungal contamination of cereal grain samples by an electronic nose. Sensors and Actuators B: Chemical 119: 425-430. https://doi. org/10.1016/j.snb.2005.12.047

Pascale, M.N., 2009. Detection methods for mycotoxins in cereal grains and cereal products. Zbornik Matice Srpske za Prirodne Nauke 117: 15-25.

Pearson, T.C. Wicklow, D.T. and Pasikatan, M.C., 2004. Reduction of aflatoxin and fumonisin contamination in yellow corn by high-speed bi-chromatic sorting. Cereal Chemistry 81: 490-498.

Peiris, K.H., Bockus, W.W. and Dowell, F.E., 2012. Infrared spectral properties of germ, pericarp, and endosperm sections of sound wheat kernels and those damaged by Fusarium graminearum. Applied Spectroscopy 66: 1053-1060.

Peiris, K.H., Dong, Y., Bockus, W.W. and Dowell, F.E., 2017. Estimation of bulk deoxynivalenol and moisture content of bulk wheat grain samples by FT-NIR spectroscopy. Cereal Chemistry 94: 677-682.

Peiris, K.H., Pumphrey, M.O. and Dowell, F.E., 2009. NIR absorbance characteristics of deoxynivalenol and of sound and Fusariumdamaged wheat kernels. Journal of Near Infrared Spectroscopy 17: 213-221.

Peiris, K.H.S., Pumphrey, M.O., Dong, Y., Maghirang, E.B., Berzonsky, W. and Dowell, F.E., 2010. Near-infrared spectroscopic method for identification of Fusarium head blight damage and prediction of deoxynivalenol in single wheat kernels. Cereal Chemistry 87: 511-517.

Pestka, J.J. and Smolinski, A.T., 2005. Deoxynivalenol: toxicology and potential effects on humans. Journal of Toxicology and Environmental Health Part B 8: 39-69.

Phillips, D.L., Xing, J., Liu, H., Pan, D.H. and Corke, H., 1999. Potential use of Raman spectroscopy for determination of amylose content in maize starch. Cereal Chemistry 76: 821-823.

Porep, J.U., Kammerer, D.R. and Carle, R., 2015. On-line application of near infrared (NIR) spectroscopy in food production. Trends in Food Science and Technology 46: 211-230.

Qiao, X., Jiang, J., Qi, X., Guo, H. and Yuan, D., 2017. Utilization of spectral-spatial characteristics in shortwave infrared hyperspectral images to classify and identify fungi-contaminated peanuts. Food Chemistry 220: 393-399.

Ravikanth, L., Jayas, D.S., White, N.D.G., Fields, P.G., and Sun, D.W., 2017. Extraction of spectral information from hyperspectral data and application of hyperspectral imaging for food and agricultural products. Food and Bioprocess Technology, 10: 1-33.

Ravikanth, L., Singh, C.B., Jayas, D.S. and White, N.D., 2015. Classification of contaminants from wheat using near-infrared hyperspectral imaging. Biosystems Engineering 135: 73-86.

Roggo, Y., Chalus, P., Maurer, L., Lema-Martinez, C., Edmond, A. and Jent, N., 2007. A review of near infrared spectroscopy and chemometrics in pharmaceutical technologies. Journal of Pharmaceutical and Biomedical Analysis 44: 683-700.

Scotter, C.N., 1997. Non-destructive spectroscopic techniques for the measurement of food quality. Trends in Food Science and Technology 8: 285-292.
Selvaraj, J.N., Zhao, L., Wang, Y., Zhao, Y.J., Xing, F.G., Dai, X.F. and Liu, Y., 2015. Mycotoxin detection-recent trends at global level. Journal of Integrative Agriculture 14: 2265-2281.

Senthilkumar, T., Jayas, D.S., White, N.D., Fields, P.G. and Gräfenhan, T., 2016a. Detection of fungal infection and ochratoxin A contamination in stored wheat using near-infrared hyperspectral imaging. Journal of Stored Products Research 65: 30-39.

Senthilkumar, T., Jayas, D.S., White, N.D., Fields, P.G. and Gräfenhan, T., 2016b. Detection of fungal infection and ochratoxin A contamination in stored barley using near-infrared hyperspectral imaging. Biosystems Engineering 147: 162-173.

Sforza, S., Dall'Asta, C. and Marchelli, R., 2006. Recent advances in mycotoxin determination in food and feed by hyphenated chromatographic techniques/mass spectrometry. Mass Spectrometry Reviews 25: 54-76.

Shahin, M.A. and Symons, S.J., 2012. Detection of fusarium damage in Canadian wheat using visible/near-infrared hyperspectral imaging. Journal of Food Measurement and Characterization 6: 3-11.

Shen, F., Liu, X., Pei, F., Li, P., Jiang, D. and Liu, Q., 2019. Rapid identification of deoxynivalenol contamination in wheat and its products by attenuated total reflectance-fourier transform infrared spectroscopy (ATR-FTIR). Food Science 40: 293-297.

Shen, F., Wu, Q., Shao, X. and Zhang, Q., 2018. Non-destructive and rapid evaluation of aflatoxins in brown rice by using near-infrared and mid-infrared spectroscopic techniques. Journal of Food Science and Technology 55: 1175-1184.

Shen, F., Wu, Q., Tang, A., Shao, X. and Jiang, D., 2016. Attenuated total reflectance-Fourier transform infrared spectroscopy (ATRFTIR) for rapid detection of aflatoxin $B_{1}$ in brown rice. Food Science 37: 187-191.

Siesler, H.W., 2011. Vibrational spectroscopy of polymers. International Journal of Polymer Analysis and Characterization 16: 519-541.

Siripatrawan, U. and Makino, Y., 2015. Monitoring fungal growth on brown rice grains using rapid and non-destructive hyperspectral imaging. International Journal of Food Microbiology 199: 93-100.

Sirisomboon, C.D., Putthang, R. and Sirisomboon, P., 2013. Application of near infrared spectroscopy to detect aflatoxigenic fungal contamination in rice. Food Control 33: 207-214.

Smith, E. and Dent, G., 2019. Modern Raman spectroscopy: a practical approach, $2^{\text {nd }}$ edition. John Wiley and Sons, Ltd., Chichester, UK.

Su, W.H., He, H.J. and Sun, D.W., 2017. Non-destructive and rapid evaluation of staple foods quality by using spectroscopic techniques: a review. Critical Reviews in Food Science and Nutrition 57: 1039-1051.

Taabu, M.S., Birech, Z. and Kaduki, K., 2015. Application of Raman spectroscopy in detection of aflatoxin $B_{1}$ in maize kernels. In: 2015 $11^{\text {th }}$ Conference on Lasers and Electro-Optics Pacific Rim (CLEOPR). Institute of Electrics and Electronic Engineers, New York, NY, USA. https://doi.org/10.1109/CLEOPR.2015.7376500

Taghizadeh, M., Gowen, A.A. and O'Donnell, C.P., 2011. The potential of visible-near infrared hyperspectral imaging to discriminate between casing soil, enzymatic browning and undamaged tissue on mushroom (Agaricus bisporus) surfaces. Computers and Electronics in Agriculture 77: 74-80. 
Talens, P., Mora, L., Morsy, N., Barbin, D.F., El Masry, G. and Sun, D.W., 2013. Prediction of water and protein contents and quality classification of Spanish cooked ham using NIR hyperspectral imaging. Journal of Food Engineering 117: 272-280.

Teena, M.A., Manickavasagan, A., Ravikanth, L. and Jayas, D.S., 2014. Near infrared (NIR) hyperspectral imaging to classify fungal infected date fruits. Journal of Stored Products Research 59: 306-313.

Thiex, N., Torma, L., Pickering, M., Nerkar, S. and Ofitserova, M., 2008. Multiresidue mycotoxin analysis in corn grain by column high-performance liquid chromatography with postcolumn photochemical and chemical derivatization: single-laboratory validation. Journal of Aoac International 92: 15-25.

Todescato, F., Antognoli, A., Meneghello, A., Cretaio, E., Signorini, R. and Bozio, R., 2014. Sensitive detection of ochratoxin A in food and drinks using metal-enhanced fluorescence. Biosensors and Bioelectronics 57: 125-132.

Turner, N.W., Subrahmanyam, S. and Piletsky, S.A., 2009. Analytical methods for determination of mycotoxins: a review. Analytica Chimica Acta 632: 168-180.

Ur-Rahman, H., Yue, X., Yu, Q., Zhang, W., Zhang, Q. and Li, P., in press. Current PCR-based methods for the detection of mycotoxigenic fungi in complex food and feed matrices. World Mycotoxin Journal 13: 139-150. https://doi.org/10.3920/WMJ2019.2455

Vankeirsbilck, T., Vercauteren, A., Baeyens, W., Van der Weken, G., Verpoort, F., Vergote, G. and Remon, J.P., 2002. Applications of Raman spectroscopy in pharmaceutical analysis. Trends in Analytical Chemistry 21: 869-877.

Vidal, M. and Amigo, J.M., 2012. Pre-processing of hyperspectral images. essential steps before image analysis. Chemometrics and Intelligent Laboratory Systems 117: 138-148.

Wagacha, J.M. and Muthomi, J.W., 2008. Mycotoxin problem in Africa: current status, implications to food safety and health and possible management strategies. International Journal of Food Microbiology 124: 1-12.

Wang, L., Sun, D.W., Pu, H. and Cheng, J.H., 2017. Quality analysis, classification, and authentication of liquid foods by near-infrared spectroscopy: a review of recent research developments. Critical Reviews in Food Science and Nutrition 57: 1524-1538.

Wang, W., Heitschmidt, G.W., Ni, X., Windham, W.R., Hawkins, S. and $\mathrm{Chu}, \mathrm{X}$., 2014. Identification of aflatoxin $\mathrm{B}_{1}$ on maize kernel surfaces using hyperspectral imaging. Food Control 42: 78-86.

Wang, W., Heitschmidt, G.W., Windham, W.R., Feldner, P., Ni, X. and Chu, X., 2015a. Feasibility of detecting aflatoxin $B_{1}$ on inoculated maize kernels surface using Vis/NIR hyperspectral imaging. Journal of Food Science 80: 116-122.

Wang, W., Ni, X., Lawrence, K.C., Yoon, S.C., Heitschmidt, G.W. and Feldner, P., 2015b. Feasibility of detecting aflatoxin $B_{1}$ in single maize kernels using hyperspectral imaging. Journal of Food Engineering 166: 182-192.
Williams, P., Manley, M., Fox, G. and Geladi, P., 2010. Indirect detection of Fusarium verticillioides in maize (Zea mays L.) kernels by near infrared hyperspectral imaging. Journal of Near Infrared Spectroscopy 18: 49-58.

Williams, P.J., Geladi, P., Britz, T.J. and Manley, M., 2012. Investigation of fungal development in maize kernels using NIR hyperspectral imaging and multivariate data analysis. Journal of Cereal Science 55: 272-278.

Wu, Q., Xie, L. and Xu, H., 2018. Determination of toxigenic fungi and aflatoxins in nuts and dried fruits using imaging and spectroscopic techniques. Food Chemistry 252: 228-242.

Wu, X., Gao, S., Wang, J.S., Wang, H., Huang, Y.W. and Zhao, Y., 2012. The surface-enhanced Raman spectra of aflatoxins: spectral analysis, density functional theory calculation, detection and differentiation. Analyst 137: 4226-4234.

Yang, D. and Ying, Y. 2011. Applications of Raman spectroscopy in agricultural products and food analysis: A review. Applied Spectroscopy Reviews 46: 539-560.

Yao, H., Hruska, Z., Kincaid, R., Brown, R.L., Bhatnagar, D., Cleveland, T.E., 2013. Detecting maize inoculated with toxigenic and atoxigenic fungal strains with fluorescence hyperspectral imagery. Biosystems Engineering 115: 125-135.

Yao, H., Hruska, Z., Kincaid, R., Ononye, A., Brown, R.L. and Cleveland, T.E., 2010. Single aflatoxin contaminated corn kernel analysis with fluorescence hyperspectral image. Spie Defense, Security, and Sensing 2010: 7676.

Yazar, S. and Omurtag, G.Z., 2008. Fumonisins, trichothecenes and zearalenone in cereals. International Journal of Molecular Sciences 9: 2062-2090.

Yu, K.Q., Zhao, Y.R., Liu, Z.Y., Li, X.L., Liu, F. and He, Y., 2014. Application of visible and near-infrared hyperspectral imaging for detection of defective features in loquat. Food and Bioprocess Technology 7: 3077-3087.

Yuan, J., Sun, C., Guo, X., Yang, T., Wang, H., Fu, S., Li, C. and Yang, $\mathrm{H}$., 2017. A rapid Raman detection of deoxynivalenol in agricultural products. Food Chemistry 221: 797-802.

Zhang, Q., Jia, F., Liu, C., Sun, J. and Zheng, X., 2014. Rapid detection of aflatoxin $B_{1}$ in paddy rice as analytical quality assessment by near infrared spectroscopy. International Journal of Agricultural and Biological Engineering 7: 127-133.

Zhang, W.W., Ye, Z.M., Jin, Y., Wang, S.Y., Zhang, L.S. and Pei, X.F., 2014. Management of mycotoxin contamination in food and feed in China. World Mycotoxin Journal 7: 53-62. https://doi.org/10.3920/ wmj2013.1553

Zhu, F., Zhang, D., He, Y., Liu, F. and Sun, D.W., 2013. Application of visible and near infrared hyperspectral imaging to differentiate between fresh and frozen-thawed fish fillets. Food and Bioprocess Technology 6: 2931-2937. 
